\title{
Time as a variable in learning on the World-Wide Web
}

\author{
ROMAN TARABAN, KIMBERLY RYNEARSON, and KATHERINE AUSTIN STALCUP \\ Texas Tech University, Lubbock, Texas
}

\begin{abstract}
Research in education, psychology, and neuroscience motivates a hypothesis that learning takes time. Support for the hypothesis was found in four replications of an upper level undergraduate course in which the material and activitiesfor $50 \%$ of the topics were delivered over the World-Wide Web. Computer records were correlated with three types of test questions: multiple-choice, short-answer, and open-ended essay questions. Positive and significant correlations with time were observed for $33 \%$ of the correlations involving multiple-choice questions, $13 \%$ of those involving short-answer questions, and $60 \%$ of those involving open-ended essay questions. An estimate of the common underlying correlation, $\rho$, equal to .35 for the four replications was significant. The data also revealed generally low overall study times and a maladaptive pattern of "cramming" before tests instead of distributing practice. In the Discussion section, we argue that computer study times can be used as a predictor of subsequent test performance, which is a measure of student learning.
\end{abstract}

New computing and communications technologies(e.g., asynchronous communication over the World-Wide Web, WWW) are creating learning environments in which students and teachers are no longer physically present. There is widespread belief that these new technologies can transform instruction for the better by providing a greater wealth of learning media and by increasing access to those resources, but this remains to be verified through controlled experiments (Maki \& Maki, 2000). The new technologies encourage more student-directed and studentcontrolled learning (Smeaton \& Keogh, 1999), but student outcomes do not always match instructors' expectations for how students will use computer-based learning tools (Taraban, Maki, \& Rynearson, 1999). Emerging technologies provide new and unique opportunities for learning and teaching (Dede, 1996), but the virtual classroom has also created new challenges for monitoring and evaluating the quality and effectiveness of instruction. How do you assess students when the traditional contexts for evaluation - the classroom, the laboratory - are no longer present? In the present paper, we examine whether computer study times, which can be recorded automatically, can provide a useful variable for predicting subsequent test performance, which is a measure of student learning.

Theoretically, the possibility that learning takes time has been considered from at least three related perspectives-educational (Bloom, 1974; Carroll, 1964; Wiley \& Harnischfeger, 1974), cognitive (Ericsson \& Charness, 1994; Simon, 1990), and neural (McClelland, McNaughton, \& O'Reilly, 1995)—with basic convergence on the conclusion that learning takes place within an extended

Correspondence should be addressed to R. Taraban, Department of Psychology, Texas Tech University, Lubbock, TX 79409-2051 (e-mail: roman.taraban@ttu.edu). time period during which information is encoded, rehearsed, elaborated, and consolidated. Walberg (1984) concluded that time was an important factor in learning, on the basis of a macro analysis of nearly 3,000 studies. The amount of time students engaged in learning was identified as one of the nine "potent, consistent, and widely generalizeable" (p. 20) factors that had a strong influence on student learning. L. W. Anderson (1993) and Fisher et al. (1980) came to similar conclusions.

Although there is strong general support for the basic contention that learning and time must be closely intertwined, there is mixed empirical support for this claim at the college level. In two experiments with undergraduates, Hakstian (1971) computed correlations between study times and performance on essay and objective (multiplechoice, true/false, matching) test questions. In the first experiment, which was conducted in an education foundations course, Hakstian found a significant negative correlation between self-reported study times and objective test questions on a midterm exam. In the second experiment, which was conducted as a laboratory experiment and was completed in one session, Hakstian found a significant positive correlation between study times that were measured unobtrusively by the experimenter and objective questions but not essay questions. There is reason to suspect self-reported study times. Indeed, the expected relation between learning and time emerged when time was recorded more objectively. However, studies that have examined student-directed learning using objective measures of time have also led to inconclusive results.

Smeaton and Keogh (1999) created 18 h of "virtual lectures" consisting of audio tracks and visuals for an undergraduate course on database. The virtual materials had a search mechanism for locating the points where specific topics were discussed. Paper copies of the visuals were distributed to the students. Fortnightly meetings 
between students and lecturers were held in order to go over difficult material and answer questions, but there were no traditional lectures. Students accessed the lectures through a WWW server, and all their interactions with the materials were recorded and time-stamped. The dependent measure in the study was performance on a 3-h exam taken at the end of the course. Smeaton and Keogh compiled five separate measures of usage: the first day the student played a presentation, the last day the student played a presentation, the number of presentations played up to and including Day 50 of the course (the one-third point - the course typically extended over a 150-day period), the number of presentations played by Day 100 of the course (the two-thirds point), and the total number of presentations played by the student. The correlation between total time spent and the exam grade did not differ significantly from zero. Furthermore, it did not matter when students viewed their first presentation or last presentation. Indeed, about half the students viewed less than half of the presentations with no apparent effect on their exam grade. Thus, these results were contrary to normal intuitions about learning and time-namely that students who started early, applied themselves consistently, and worked through all the lessons would be rewarded with higher test grades.

Evidence that was more favorable to a connection between learning and time was reported by Taraban and Rynearson (1998). In two preliminary studies, the material for about half of the topics in an upper level psychology course on cognition was provided to students on floppy diskettes. Time-stamped records of students' interactions with the modules were automatically recorded on the floppies, which were subsequently returned to the instructor. In the first study, the relationship between time and learning was examined when students used four modules independently. No lectures were provided to students on the topics covered in the modules- the modules were students' sole source of information. Correlations between computer study time and test questions for the four modules were $.40,-.07, .55$, and .52 . Because the hypothesis about time and learning was directional, one-tailed tests were appropriate, with $r=.28$ for significance at the .05 level. These results suggested that study times could be used as a predictor of subsequent test performance. In a following semester, the modules were used to extend the material in the class lectures. Class lectures were used to introduce the topics in a module, to go over difficult concepts and computations, and to answer students' questions. Positive correlations between computer study times and test grades were found in six of six cases: $.31, .39$, $.44, .19, .12$, and $.29(r=.29$ for significance at the .05 level). Thus, when computer-based materials were used independently or as a supplement, correlations between computer time and test performance were significant about $70 \%$ of the time.

In the present case studies, the upper level cognition course used by Taraban and Rynearson (1998) was used for four additional case studies. The modules were re- vised to include a set of common elements (described in the next section), and the modules were distributed over a larger portion of the curriculum. Although there were no direct tests of these changes, they did create a common look and feel for the learning tools. The modules were provided to students over the WWW instead of on floppy disks. Whereas the test scores in Taraban and Rynearson were composite scores consisting of points for true/false, multiple-choice, short-answer, and short essay questions, the present case studies separated study time effects according to question type.

The major question was whether computer study times associated with undergraduate instruction reliably correlated with test performance. This relationship was tested with three types of test questions: multiple-choice and short-answer questions (Case Studies 1 and 2), and openended essay questions (Case Studies 3 and 4). Strong correlations would support the hypothesis that learning takes time-in this case, involving a deliberate allocation of study time to achieve performance goals. A related question was how much time students spent working with the materials. In general, instructors know how much material they assign and how well students do on tests over that material, but they know less about how much time students spend studying the material. Computer records can provide a partial answer to this question. Finally, we also wanted to know whether students distributed their study times (cf. Taraban et al., 1999). The benefits of spaced study have been known for nearly a century (Lyon, 1914; cf. Dempster, 1989).

\section{OVERVIEW OF THE CASE STUDIES}

\section{Course Materials}

The traditional lecture-test format in an upper division psychology course on cognition was substantially augmented by computer modules delivered via the WWW. The module topics were based on central issues or theoretical approaches in cognitive psychology. The modules consisted primarily of text screens that were composed by the first author. The content was based primarily on John R. Anderson's (1995) Cognitive Psychology and Its Implications and George Luger's (1994) Cognitive Science textbooks. Each module was divided into subtopics that students could access in a nonlinear fashion using a menu screen. The primary text was supplemented with several distinct elements that were available to students in nearly all the lessons.

Checklist questions. Each module included a set of study questions that the students were encouraged to review before beginning the module. The questions were accessible through the menu.

Comprehension monitoring activities. Modules typically included interactive screens that asked the students to respond using the computer keyboard. In some instances, the students provided short answers. In other cases, the students were required to calculate a quantity (e.g., a probability). Immediate feedback was provided for all responses.

Supplemental screens. The primary text was supplemented with explanatory comments or definitions of difficult terms and, occasionally, graphs, tables, and figures. Each module tended to have between one and three extended quotes (approximately one or two textbook pages) from one of several textbooks. These additional learning resources were retrieved via the students' intentional mouse clicks. 
The modules covered the following: seven major themes in cognitive psychology (7T), human and artificial intelligence (HA), connectionism (CO), connectionist models $(\mathrm{CM})$, propositional representation (PR), propositional networks (PN), interference and facilitation in memory retrieval (IF), syntactic representation (SR), language and cognition (LC), decision-making heuristics (DM), probability concepts (PC), and Bayes theorem and prospect theory (BT). The content spanned about $50 \%$ of the major course topics in all four case studies. The modules provided the primary source of text-based information for these topics, although many of the topics were drawn from a supplemental textbook for the course, which the students could also access for some of the same and related information.

The students' perceptions of the value and quality of the modules were monitored throughout the period of development and delivery. In the two semesters prior to those reported in this paper (see Taraban \& Rynearson, 1998), the students responded to several short questions about their satisfaction with the computer modules. Using Likert-type ratings on a scale of 1 (low) to 5 (high), the students indicated that they enjoyed (4.0) the modules and found them helpful (4.0); both mean ratings were significantly higher $(p s<.05)$ than the neutral rating (3.0). The students preferred the computer modules over lectures (3.64 vs. 3.00), and they preferred lectures with computer modules over computer modules alone (4.46 vs. 3.00$)$ (both $p$ s <.05). When about $25 \%$ of the course content was covered in computer modules, the students indicated a preference for a $25 \%$ increase, and in a subsequent semester when about $45 \%$ was covered, the students indicated a preference for a $40 \%$ increase- both were significant increases $(p s<.05)$. The students' comments on course evaluations for all case studies, including those reported in this paper, were typically positive, with particular appreciation expressed for the comprehension monitoring activities and remote access capabilities. In Case Study 4, reported in this paper, the students were given a short questionnaire early in the semester to assess their perceptions of the usability of the web modules. The students unanimously responded "yes" to the question, "Are you generally comfortable with the web modules?" and unanimously responded "no" to the question, "Would you like additional training to help you use the web modules?"

\section{General Procedure for the Modules}

After the students completed a password-protected log-in protocol that gave them access to the Web site home page, they navigated to a module and accessed subtopics within the module using a menu. As the students read through the text and interacted with the activities, a record was unobtrusively created that included measures such as the time spent on various parts of the module and the students' accuracy on the interactive activities. These records were not accessible to the students. The software did not allow the students to print computer screens; therefore, the computer records provided a fairly accurate indication of the amount of time the students spent reading the text, making notes, and interacting with the activities. The modules were assigned according to the class syllabus. The topic dates spanned the entire semester. The remaining topics for the course (e.g., memory, problem solving, the development of expertise) were taught using standard lectures.

In-class tests were scheduled approximately every 2 weeks. In the first two case studies, the in-class tests consisted of multiplechoice and short-answer questions. Short-answer questions included brief descriptions or explanations, filling-in terms, and calculating values (e.g., Bayesian probabilities). In the third and fourth case studies, in-class tests consisted of open-ended essay questions. The students were provided with study questions that listed the major test topics in advance of all tests. The duration of the tests was a full class period $-1 \mathrm{~h}$ and $20 \mathrm{~min}$.

The students registered for the course in the standard fashion. The modules were described to the students on the first day of class, and they were informed that the computer would carry out auto- matic data collection. The students had the option to decline to have their data included in any reports, without penalty. No students declined. Some students dropped the course sometime before taking the first $(n=4)$ or second $(n=7)$ test. These students were not included in the analyses: 2 students in Case Study 1, 1 in Case Study 2, 4 in Case Study 3, and 4 in Case Study 4. In addition, the computer records for 3 students in Case Study 4 were corrupted and could not be reconstructed.

\section{Design}

The time measures used for the analyses were total times spent using the computer modules. Results for finer grained analyses that looked at specific components within the modules (e.g., comprehension monitoring activities) were similar to the results for total times and did not affect the conclusions, so they are not presented here. Because the hypothesis about time and performance was directional, one-tailed probabilities were computed. Significance was set at $\alpha=.05$. In addition to time, grade-point averages (GPA) and absences from lectures on module topics were also included. GPA provided an indication of a student's past academic success and, indirectly, a measure of a student's capacity for study and test taking. The a priori hypothesis was that good students studied more. Absences were relevant because useful information on a topic was presented during the missed lecture. The a priori hypothesis was that absences would lower the students' test performance. An alternative hypothesis - that the students would compensate for missed classes with longer computer times - did not fit our profile of a weak student, who usually missed class as well as other important course elements.

\section{CASE STUDY 1}

\section{Participants}

The 20 participants attended Texas Tech University during the regular fall term. Sixty percent $(n=12)$ were psychology majors; the remaining 8 participants represented eight distinct majors. The ethnic distribution was $75 \%$ Caucasian and $25 \%$ Hispanic. The median age was 21 years (range 19-46 years). All but 1 of the participants were juniors or seniors, based on the number of earned credit hours. The participants' mean GPA was 2.69 ( $S D=$ 0.54 ) on a 4 -point scale $(1=\mathrm{D}, 2=\mathrm{C}, 3=\mathrm{B}, 4=\mathrm{A})$.

\section{Results}

Pearson correlations of computer times for test topics, GPA, absences from lectures for test material, points on multiple-choice test questions, and points on shortanswer test questions are shown in Table 1. There was only slight evidence that "smart" students studied more, as indicated by correlations between computer time and GPA.

Table 1

Pearson Correlations for Computer Times in Case Study 1

\begin{tabular}{clcccr}
\hline Test & \multicolumn{1}{c}{ Topics } & GPA & AB & MC & SA \\
\hline 1 & 7T, HA, AC & .01 & -.21 & .30 & -.16 \\
2 & CO, CM & .00 & -.11 & .27 & .05 \\
3 & MM, PR, PN & .08 & .11 & $.43^{*}$ & -.09 \\
4 & SR, LC & .07 & -.30 & .30 & .25 \\
5 & DH, PC, BT & .16 & $-.40^{*}$ & & $.41^{*}$ \\
\hline
\end{tabular}

Note $-N$ for all correlations $=20$. GPA, grade-point averages; $\mathrm{AB}, \mathrm{ab}-$ sences from lectures on the associated topics; MC, points on multiplechoice test questions; SA, points on short-answer test questions. See the text for topic abbreviations. ${ }^{*} p<.05$ (one-tailed). 
Higher absence rates were associated with lower computer times in four of five analyses, suggesting that the students who missed the lectures did not try to compensate for their absences by spending more time at the computer. All the correlations between computer times and multiple-choice test scores were positive, and one out of four $(25 \%)$ was significant. Only one out of five $(20 \%)$ of the correlations between computer time and shortanswer scores was significant.

The typical span between tests over the material described in Table 1 was about 2 weeks. The average total time that the students spent at the computer during that 2-week span was about $145 \mathrm{~min}$. Average total time did not vary greatly as a function of test topics or placement in the course calendar: Test 1, $152 \mathrm{~min}$; Test 2, $146 \mathrm{~min}$; Test 3, $164 \mathrm{~min}$; Test 4, $107 \mathrm{~min}$; Test 5, $148 \mathrm{~min}$. Figure $1 \mathrm{~A}$ shows that the total study time was not uniformly distributed across this time span but that the students went to the computer 1 or 2 days before the test. Figure $1 \mathrm{~B}$ shows that the pattern of "cramming" before a test was uniformly adopted by nearly all the students. (The local peak at Day 12 preceding the test was most probably the result of an all-class orientation to the modules.)

\section{CASE STUDY 2}

Case Study 2 was a replication of Case Study 1 that was conducted in the following summer term. Students met 5 days a week for 6 weeks. There were fewer tests and shorter spans between tests. The content was comparable, but there was more emphasis on written assignments to keep the students more uniformly engaged with the materials.

\section{Participants}

The 18 participants attended Texas Tech University during a summer term. Eighty-three percent $(n=15)$ were psychology majors; the remaining 3 participants represented three distinct majors. The ethnic distribution was $83 \%$ Caucasian $(n=15), 6 \%$ Hispanic $(n=1)$, and $11 \%$ African-American $(n=2)$. The median age was 21 years (range 19-27 years). Eleven percent of the participants $(n=2)$ were sophomores; the remaining 16 were juniors or seniors. The participants' mean GPA was $2.98(S D=0.56)$.

\section{Results}

Pearson correlations were positive for five out of five of the correlations between computer times and test scores (see Table 2). One of the two (50\%) correlations with multiple-choice test scores was significant. The correlations with short-answer questions were uniformly positive and stronger, relative to Case Study 1; however, none reached significance. There was a trend for GPA to be positively correlated with computer time. When the effects of GPA were partialed out of the correlations between computer time and test performance, the correlations remained positive (and, in two cases, significant), suggesting a role for time and learning that was independent of individual differences that were captured by GPA. Attendance data were not collected.

\section{CASE STUDY 3}

In the first two case studies, correlations between computer study times and test scores were in the right direction in 12 out of $14(86 \%)$ analyses. However, the strength of these correlations was reliable in only 3 out of 14 (21\%) analyses. The test questions made diverse demands of students: cued recall for the multiple-choice questions; and recall for short lists of items, for brief descriptions or explanations, and for formulas and calculations. This diversity precluded any easy analysis of how time related to test questions. A simple and uniform test format was adopted for the next two case studies, consisting of openended essay questions. The questions to which the students responded were stated generally and used a module title for the topic (e.g., "Discuss Propositional Representations"). Prior to each test, the students were given the test questions with several suggestions for the kinds of information that would be relevant. There were two benefits to using open-ended essay questions: (1) a uniform grading procedure was applied (described in the Results section), and (2) the students had a clear idea of the structure of the tests.

\section{Participants}

The 30 participants attended Texas Tech University during a regular fall term. Ninety percent $(n=27)$ were psychology majors; the remaining 3 participants represented three distinct majors. The ethnic distribution was $63 \%$ Caucasian $(n=19), 23 \%$ Hispanic $(n=7)$, and $13 \%$ African-American $(n=4)$. The median age was 22 years (range 20-26 years). Seventy-seven percent of the participants $(n=23)$ were juniors or seniors, $13 \%$ $(n=4)$ were sophomores, and 10\% $(n=3)$ were in their freshman year, based on the number of earned credit hours. The participants' mean GPA was $2.75(S D=0.74)$.

\section{Results}

The grading of the essay responses was carried out as follows. The students were assigned one point for each substantive piece of information, which could be a main point or substantive detail. The points were tallied and assigned as the score for that question. For half the questions, the course instructor and the graduate teaching assistant for the course graded the responses independently. Interrater reliability for this sample was high $[r(148)=$ $.93, p<.01]$. The instructor assigned the final scores. The computer records containing study times were accessed at the end of the semester after all the grading had been completed.

Pearson correlations between computer time and GPA were positive for 10 out of 10 essay questions, and they were significant in 9 out of 10 analyses, indicating that 

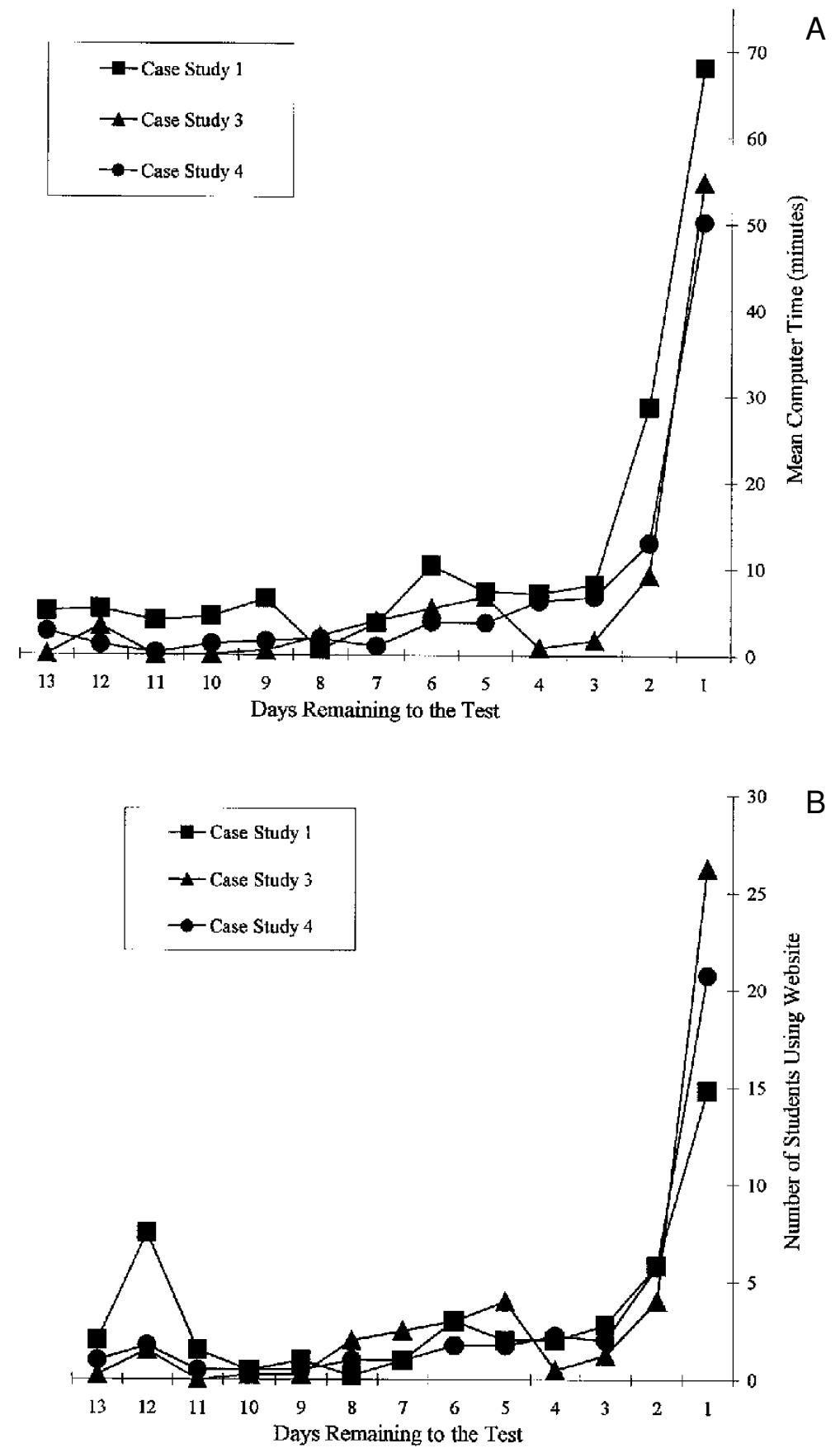

Figure 1. (A) Mean student computer times preceding class tests for Case Studies 1, 3, and 4. (B) Mean number of students accessing the Web site preceding class tests for Case Studies 1, 3, and 4 .

higher GPA was associated with longer study times, as shown in Table 3. Class absences were negatively correlated with computer time for 8 out of 10 essay questions, significantly correlated with time in two analyses, with higher absence rates associated with lower computer times. This suggested that the students were not using the computer lessons to compensate for missed lectures. Instead, the students who missed more lectures used the computer modules less. All the correlations between computer times and essay test scores were positive, and 7 of the $10(70 \%)$ correlations were significant. All the significant correlations remained positive and 2 remained 
Table 2

Pearson Correlations for Computer Times in Case Study 2

\begin{tabular}{clccccc}
\hline Test & \multicolumn{1}{c}{ Topics } & GPA & MC & MC|GPA & SA & SA|GPA \\
\hline 1 & 7T, HA, AC, MM & .26 & .35 & .25 & .27 & .14 \\
2 & CO, CM, PR, PN, IF & .13 & $.41 *$ & $.42 *$ & .37 & $.44 *$ \\
3 & SR, LC & .21 & & & .27 & .17 \\
\hline
\end{tabular}

Note- $N$ for all correlations $=18$. GPA, grade-point averages; MC, points on multiple-choice test questions; SA, points on short-answer test questions; MC |GPA and SA |GPA, partial correlations adjusted for gradepoint average. See the text for topic abbreviations. $* p<.05$ (one-tailed).

significant when partial correlations were calculated using GPA. Positive partial correlations indicated that time was important to test performance even after adjustments were made for individual students' past academic successes and underlying skills.

The average total time that the students spent at the computer during the typical 2-week span between tests was about $100 \mathrm{~min}$. Average study time varied little as a function of topic or time in the semester: Test 1, $99 \mathrm{~min}$; Test 2, $105 \mathrm{~min}$; Test 3, $97 \mathrm{~min}$; and Test 4, $100 \mathrm{~min}$. Figure $1 \mathrm{~A}$ shows that these students went to the computer 1 or 2 days before the test, as did the students in Case Study 1 . Figure 1B shows that nearly all students adopted a pattern of "cramming" before tests.

\section{CASE STUDY 4}

Case Study 4 was a replication of Case Study 3 that was conducted in the following spring term. Prior to beginning each in-class test, the students were asked to report how much time they spent at the computer working on the modules for that test. These self-reports were compared with the computer records.

\section{Participants}

The 27 participants attended Texas Tech University during a regular spring term. Eighty-five percent $(n=23)$ were psychology majors; the remaining 4 participants represented four distinct majors. The ethnic distribution was $78 \%$ Caucasian $(n=21), 18 \%$ Hispanic $(n=5)$, and $4 \%$ African-American $(n=1)$. The median age was 21 years (range 18-46 years). Seventy percent of the participants $(n=19)$ were juniors or seniors, $22 \%(n=$ 6 ) were sophomores, 1 student was in her freshman year, and 1 student was a graduate student, based on the number of earned credit hours. The participants' mean GPA was $2.92(S D=0.65)$.

\section{Results}

The grades for 4 of the 10 questions were assigned by the graduate teaching assistant for the course, as described for Case Study 3; the remaining grades were assigned by the course instructor. Interrater reliability was high $[r(23)=.93, p<.01]$, based on one question graded by both the instructor and teaching assistant.

The correlations between computer times and GPA and absences were in the predicted direction in about half the analyses (see Table 4). Over half of the correlations between computer time and absences were positive, and two of these were significant. These positive correlations suggested that some students who missed class may have been using the modules in a compensatory fashion.

Nine of 10 correlations between computer time and points for essay responses were positive; 5 of these were significant. When partial correlations were computed using GPA, these correlations remained positive and significant. On average, the students spent a total of $105 \mathrm{~min}$ at the computer during the typical 2-week span between tests. This figure was nearly identical to the average total time in Case Study 3. However, these students spent more time at the computer at the beginning of the semester and less time as the semester progressed: Test 1, $123 \mathrm{~min}$; Test 2, $127 \mathrm{~min}$; Test 3, $95 \mathrm{~min}$; Test 4, $75 \mathrm{~min}$. The students' distributions of study times in this study were similar to the patterns found in the previous case studies (see Figures $1 \mathrm{~A}$ and $1 \mathrm{~B}$ ).

The students' self-reports of times spent at the computer during the periods between tests were significantly higher than the times that were automatically recorded by the computer, as summarized in Table 5. Each of the discrepancies between actual times and the students' self-reports was significant. The correlations between the students' self-reports and computer times were also significant (see Table 5), suggesting that the students generally tended to exaggerate times in their self-reports but that their self-reports were consistent with the relative levels within the group.

\section{ESTIMATING THE COMMON CORRELATION ACROSS CASE STUDIES}

The pattern of correlations across the case studies was indicative of a reliable association between computer study times and in-class test performance. In order to estimate the common correlation, $\rho$, across these studies, the following analysis was carried out. First, a weighted correlation was calculated separately for each case study

Table 3

Pearson Correlations of Computer Times in Case Study 3

\begin{tabular}{clllll}
\hline Test & Topics & GPA & AB & Essay & Essay|GPA \\
\hline 1 & HA & $.68 * * *$ & $-.32 *$ & $.68 * * *$ & $.48 * *$ \\
1 & AC & $.52 * *$ & $-.36 *$ & $.43 * *$ & .30 \\
2 & MM & $.50^{* *}$ & -.25 & $.48 * *$ & .27 \\
2 & CO & $.51 * *$ & -.11 & .06 & $-.39 *$ \\
2 & CM & $.59 * * *$ & -.11 & $.40 *$ & .07 \\
3 & PR & .29 & -.27 & $.38 *$ & .28 \\
3 & PN & $.39 *$ & -.07 & .27 & .06 \\
3 & IF & $.35 *$ & .23 & .23 & .08 \\
4 & SR & $.41 *$ & .10 & $.61 * * *$ & $.50 * *$ \\
4 & LC & $.68 * * *$ & -.09 & $.61 * * *$ & .21 \\
\hline
\end{tabular}

Note- $N$ for correlations $=30,30,27$, and 26, for Tests $1,2,3$, and 4, respectively. GPA, grade-point averages; AB, absences from lectures on the associated topics; Essay, points on essay questions; Essay | GPA, partial correlations adjusted for grade-point average. See the text for topic abbreviations. ${ }^{*} p<.05$ (one-tailed). $* * p<.01$ (one-tailed). $* * * p<.001$ (one-tailed). 
Table 4

Pearson Correlations of Computer Times in Case Study 4

\begin{tabular}{ccrcll}
\hline Test & Topics & GPA & AB & Essay & Essay|GPA \\
\hline 1 & HA & .19 & n.a. & $.57^{* * *}$ & $.56^{* * *}$ \\
1 & AC & .18 & n.a. & $.47^{* *}$ & $.47^{* *}$ \\
2 & MM & -.29 & $.41^{*}$ & $.37^{*}$ & $.38^{*}$ \\
2 & CO & -.03 & -.08 & .13 & .17 \\
2 & CM & -.07 & $.47^{* *}$ & .08 & .10 \\
3 & PR & .10 & -.12 & .13 & .10 \\
3 & PN & -.05 & .08 & .19 & .26 \\
3 & IF & .12 & .04 & $.40^{*}$ & $.39^{*}$ \\
4 & SR & .09 & -.21 & .00 & -.08 \\
4 & LC & .00 & .16 & $.45^{*}$ & $.48^{* *}$ \\
\hline
\end{tabular}

Note $-N$ for correlations $=27,26,26$, and 25 , for Tests $1,2,3$, and 4 , respectively. GPA, grade-point averages; $\mathrm{AB}$, absences from lectures on the associated topics; Essay, points on essay questions; Essay |GPA, partial correlations adjusted for grade-point average; n.a., data not available. See the text for topic abbreviations. $* p<.05$ (one-tailed). $* * p<.01$ (one-tailed). $\quad * * * p<.001$ (one-tailed).

by applying a $z$-transformation (Hedges \& Olkin, 1985, p. 231) to the correlations shown in Tables $1-4$. These weighted $r$ values are shown in Table 6. Next, a metaanalysis was carried out using the weighted $r$ and $N$ of each case study using a $z$-transformation (Hedges \& Olkin, 1985, pp. 231-232). This yielded an estimate of $\rho$, the common correlation across the four case studies, equal to .35 , which was significant based on a $z$ test, with $p<$ .001 (two-tailed). The lower limit of the $95 \%$ confidence interval was estimated at .12 and the upper limit at .51.

\section{DISCUSSION}

\section{Time as a Variable in Learning}

The underlying hypothesis in the present investigations was that learning takes time. This premise can be supported from at least three different perspectives. Beginning in the 1960s, researchers in education began emphasizing the importance of allocating time for learning (Carroll, 1964; Fisher et al., 1980; Wiley \& Harnischfeger, 1974). Stallings (1980) regarded time on task as one of the most useful variables that came out of research on teaching in the 1970s. Allocated school time and learning time were concepts that gave teachers a straightforward way to think about increasing student achievement. Instructional paradigms, such as the mastery learning approach of Bloom (1974), assumed that nearly all students could achieve task mastery-even reach the highest levels of achievement (Bloom, 1985)_-given sufficient time and practice. From a cognitive perspective, time defines essential limits (law-like "invariants") of human information processing (Simon, 1990). For instance, it takes about $10 \mathrm{msec}$ to carry out the most elementary information processes, it takes about $9 \mathrm{sec}$ to memorize a three-letter word, and it takes about $30 \mathrm{sec}$ to memorize a three-consonant nonsense string. The transfer of information into memory in the most ordinary circumstances and across the life span can be expressed simply in terms of "bits" of information per second (Landauer, 1986). From a neural perspective, learning and memory depend on synaptic changes. At the level of individual cells, repetitive stimulation along a pathway results in more efficient transmission along the pathway. At the level of memory systems, the process of consolidation of information into memory can take up to 15 years (McClelland et al., 1995). The message from all three perspectives is that information transfer in human memory systems does not happen instantaneously or magically but is limited largely by a time factor.

The major question was whether computer study times associated with undergraduate instruction reliably correlated with test performance, which was considered a measure of how much a student learned in the course. In four separate semesters, positive and significant correlations with time were observed for $33 \%$ of the correlations involving multiple-choice questions, $13 \%$ of those involving short-answer questions, and $60 \%$ of those involving open-ended essay questions. An estimate of $\rho=$ .35 for the four case studies was highly significant. Overall, the significant correlations between study time and test performance were consistent with the hypothesis that learning takes time. These results disagree with the findings of Smeaton and Keogh (1999), who reported nonsignificant correlations between five separate measures of computer usage and test performance. The results are also inconsistent with Hakstian's (1971) Experiment 1, in which there was a significant negative correlation between study time and objective test questions (multiplechoice, true/false, matching) and no significant correlation for essay questions; the results are only partially consistent with Hakstian's Experiment 2, in which there was a significant correlation for objective test questions but not for essay questions.

\section{Students' Time Commitment}

A related question in this study was how much time the students spent working with the materials. Overall, the amount of time the students spent studying the modules seems alarmingly low, considering that the modules covered about $50 \%$ of the primary course content. The average total times were as follows: Case Study 1, 11.96 h; Case Study 2, 9.34 h; Case Study 3, 6.69 h; and Case Study 4, $7.00 \mathrm{~h}$. Part of the reduction in computer time in Case Studies 3 and 4 could be attributed to the open-ended essay format employed in those studies. The uniformity and open-ended nature of the questions may have allowed the students to prepare more efficiently. Consistent with this possibility, a student in Case Study 1 commented

Table 5

A Comparison of Students' Self-Reports and Computer Times in Case Study 4

\begin{tabular}{cccc}
\hline $\begin{array}{c}\text { Mean Self-Reported } \\
\text { Test }\end{array}$ & $\begin{array}{c}\text { Mean Computer } \\
\text { Computer Time (hours) }\end{array}$ & $\begin{array}{c}\text { Pearson Correlation } \\
\text { Time (hours) }\end{array}$ & Coefficients \\
\hline 1 & 5.31 & $2.06^{* *}$ & $.58^{*}$ \\
2 & 4.46 & $2.12^{* *}$ & $.47^{*}$ \\
3 & 3.40 & $1.62^{* *}$ & $.46^{*}$ \\
4 & 2.88 & $1.25^{* *}$ & $.48^{*}$ \\
\hline$* p<.05$ (two-tailed) $* * p<.01$ (two-tailed)
\end{tabular}


Table 6

Weighted Correlations for Computer Times and Test Scores

\begin{tabular}{ccc}
\hline Case Study & Sample Size & Weighted $r$ \\
\hline 1 & 20 & .20 \\
2 & 18 & .34 \\
3 & $28^{*}$ & .43 \\
4 & $26^{*}$ & .29 \\
\hline
\end{tabular}

* Based on the harmonic mean of the students who took the tests (see Tables 3 and 4).

that the tests forced her to prepare several different ways in order to do well on multiple-choice, short-answer, and essay questions.

The results summarized in Table 5 indicate that the students uniformly exaggerated their computer times in their self-reports. This may be due to the students' desire to project a favorable image, but there are other possibilities. The students may not have been good at monitoring the actual time that they were engaged in study on the computer. It is also possible that the students' self-reports included the times they spent studying from notes. In this case, the computer times underestimated total study times. However, even if we were to accept the students' selfreports (Case Study 4), the total times are still low.

\section{Distribution of Study Times}

Besides information about individual students, the computer study times also provided information about the effectiveness of the computer-based learning media. There is a general expectation that computer-based and distance technologies will change the way students study, freed as they are from the bricks and mortar of the traditional classroom. Taraban et al. (1999) collected selfreports of study times from college students and compared these with computer study times and hit rates. They found no essential differences in patterns of study behaviors in the traditional classroom compared with two psychology courses with computer-based learning aids. Nearly all the students showed a maladaptive pattern of cramming immediately before tests, instead of the more beneficial pattern of spacing study (Dempster, 1989).

The present data allowed us to compare study time distributions during three long semesters (Case Study 1 was reported in Taraban et al., 1999). One difference between the courses has already been mentioned-the use of multiple-choice and short-answer test questions for Case Study 1 and open-ended essay questions for Case Studies 3 and 4. Otherwise, the courses were very similar. The typical time span between exams was approximately 2 weeks. Figures 1A and 1B depict mean computer times and number of students accessing the Web site, averaged across the class tests. The figures show that students in all three semesters "crammed" before tests. The students studied primarily the day preceding the test, and the pattern did not vary considerably as a function of the test format.
The study patterns depicted in Figures $1 \mathrm{~A}$ and 1B, compared with self-reports of students in traditional classrooms, are inconsistent with the expectation that computerbased and distance technologies will automatically change the way students study. Deliberate changes to the curriculum may be necessary. Taraban et al.'s (1999) Case Study 3 showed that class requirements changed the way students distributed their computer times.

\section{Conclusion}

New computer technologies have enabled explorations into questions about when and under what circumstances learning takes place. The consistent positive correlations in the present case studies suggest that computer times can be used to gauge student learning. Relatedly, computer study times and Web site "hit rates" provide useful information about the impact of the materials themselves. Computer-based and distance-learning technologies place more control of learning in the hands of students. However, if students use computer materials primarily for cramming before exams (cf. Taraban et al., 1999), or if they fail to access the materials at all (Smeaton \& Keogh, 1999), there may be a need to introduce changes into how a course is administered (Maki \& Maki, 2000). In general, much can be gained by monitoring how students spend their time.

\section{REFERENCES}

ANDERSON, J. R. (1995). Cognitive psychology and its implications (4th ed). New York: Freeman.

Anderson, L. W. (1993). What time tells us. In L. W. Anderson \& H. J. Walberg (Eds), Timepiece: Extending and enhancing learning time (pp. 15-22). Washington, DC: National Association of Secondary School Principals.

BLoom, B. S. (1974). Time and learning. American Psychologist, 29, 682-688.

BLoom, B. S. (ED.) (1985). Developing talent in young people. New York: Ballantine.

Carroll, J. (1964). A model of school learning. Teachers College Record, 64, 723-733.

DEDE, C. (1996). The evolution of distance education: Emerging technologies and distributed learning. American Journal of Distance Education, 10, 4-36.

DEMPSTER, F. (1989). Spacing effects and their implications for theory and practice. Educational Psychology Review, 1, 309-330.

ERICSSON, K. A., \& CHARness, N. (1994). Expert performance: Its structure and acquisition. American Psychologist, 49, 725-747.

Fisher, C., Berliner, D., Filby, N., Marliave, R., Cahen, L., \& Dishaw, M. (1980). Teaching behaviors, academic learning time, and student achievement: An overview. In C. Denham \& A. Lieberman (Eds.), Time to learn (pp. 7-32). Washington, DC: U. S. Department of Education.

HaKstian, A. (1971). The effects of type of examination anticipated on test preparation and performance. Journal of Educational Research, 64, 319-324.

HedGes, L., \& Olkin, I. (1985). Statistical methods for meta-analysis. San Diego: Academic Press.

LANDAUER, T. (1986). How much do people remember? Some estimates of the quantity of learned information in long-term memory. Cognitive Science, 10, 477-493.

Luger, G. (1994). Cognitive science. San Diego: Academic Press. LyON, D. (1914). The relation of length of material to time taken for 
learning, and the optimum distribution of time. Journal of Educational Psychology, 5, 1-9.

MAKI, W. S., \& MAKI, R. H. (2000). Evaluation of a Web-based introductory psychology course: II. Contingency management to increase use of on-line study aids. Behavior Research Methods, Instruments, \& Computers, 32, 240-245.

McClelland, J. L., McNaughton, B., \& O’Reilly, R. (1995). Why there are complementary learning systems in the hippocampus and neocortex: Insights from the successes and failures of connectionist models of learning and memory. Psychological Review, 102, 419-457. Simon, H. A. (1990). Invariants of human behavior. Annual Review of Psychology, 41, 1-19.

Smeaton, A., \& Keogh, G. (1999). An analysis of the use of virtual delivery of undergraduate lectures. Computers \& Education, 32, 83-94.

STALLINGS, J. (1980). Allocated academic learning time revisited, or beyond time on task. Educational Researcher, 9(11), 11-16.
Taraban, R., Maki, W. S., \& Rynearson, K. (1999). Measuring study time distributions: Implications for developing computer-based courses. Behavior Research Methods, Instruments, \& Computers, 31, 263-269. Taraban, R, \& Rynearson, K. (1998). Computer-based comprehension research in a content area. Journal of Developmental Education, 21(3), 10-18.

WALBERG, H. (1984). Improving the productivity of America's schools. Educational Leadership, 41, 19-27.

Wiley, D., \& HARnischFEger, A. (1974). Explosion of a myth: Quantity of schooling and exposure to instruction, major educational vehicles. Educational Researcher, 4, 7-12.

(Manuscript received October 11, 2000; revision accepted for publication March 10, 2001.) 